Issue no. $25 / 2018$

\title{
FAILURE OF THE SUPERPOWERS (U.S.A., RUSSIA, JAPAN) TO HANDLE LARGE NUCLEAR EVENTS
}

Ori Nissim LEVI ${ }^{19}$

\section{DOI:10.24193/OJMNE.2018.25.06}

\begin{abstract}
The current article describes research about large nuclear events that occurred around the world, key failures that led to defective handling, presents the need f or better preparedness than currently exists and how this can be provided using the ONDM model. The Operational Nuclear Defense Model - ONDM is a model that can be applied to cope with nuclear disasters around the world at a policy making level in the area of CBRNE Defense (Chemical, Biological, Radiological, Nuclear, and Explosive materials). In this case, a nuclear event refers to a large scale nuclear incident rated at the highest level (6-7 in the International Nuclear and Radiological Event Scale - INES) caused by bombing, malfunction, terrorist act or natural disaster that demands treatment and a public response on a governmental level. A study of previous incidents teaches us that there were recurring failures in dealing with nuclear events, and even reveals that lessons have not yet been learned from past events and current preparedness for future events is lacking. This in contrast to a greater need for preparedness in these tense times. This research revealed critical failures, which are responded to in the developed model.
\end{abstract}

Keywords: CBRNE, ABC, Homeland Security, Governmental, ONDM, Mega event, Nuclear, Risk analysis assessment, Civil defense.

\section{Introduction}

The article presents the argument that models existing today in many countries around the world to cope with future large scale nuclear events (INES 6-7) are lacking and do not provide an appropriate response to preparedness, management and rehabilitation.

\footnotetext{
19 Expert in nuclear defense; has a B.Sc and MBA and is doing his PhD doctoral research in managing nuclear risks at a governmental level, preparations for nuclear incidents, coping during events and national rehabilitation after a nuclear event. He is a member of AFNA (Academic Forum for Nuclear Awareness). An active Colonel in the Israeli Defense Forces Reserves, serving in operational roles and responsible for the construction of large-scale exercises in emergency areas such as earthquakes, tsunamis, war, conventional and nonconventional weapons.
}

For more information ori.levi@ONDM.co or www.ONDM.co 
Issue no. $25 / 2018$

Research of past incidents reveals that in coping with large scale nuclear events decision makers have not learned lessons and have repeated the same mistakes made before.

The key failures which the ONDM model addresses were identified through analysis of past incidents, studying the data of countries' existing models to cope with such disasters and the personal experience of the researcher. This was done in light of theoretical approaches, which where the realistic approach to international relations (Dobson, 2002; Donnelly, 2000; Morgenthau, 1978) and theoretical approaches to leaders' decision making in general and in times of crisis in particular (Omer, 2008; Redd \& Mintz, 2013).

\section{Arguments}

Models existing today in many countries around the world to deal with future major nuclear events (INES 6-7) are lacking and fail to provide an appropriate response to preparation, management and rehabilitation.

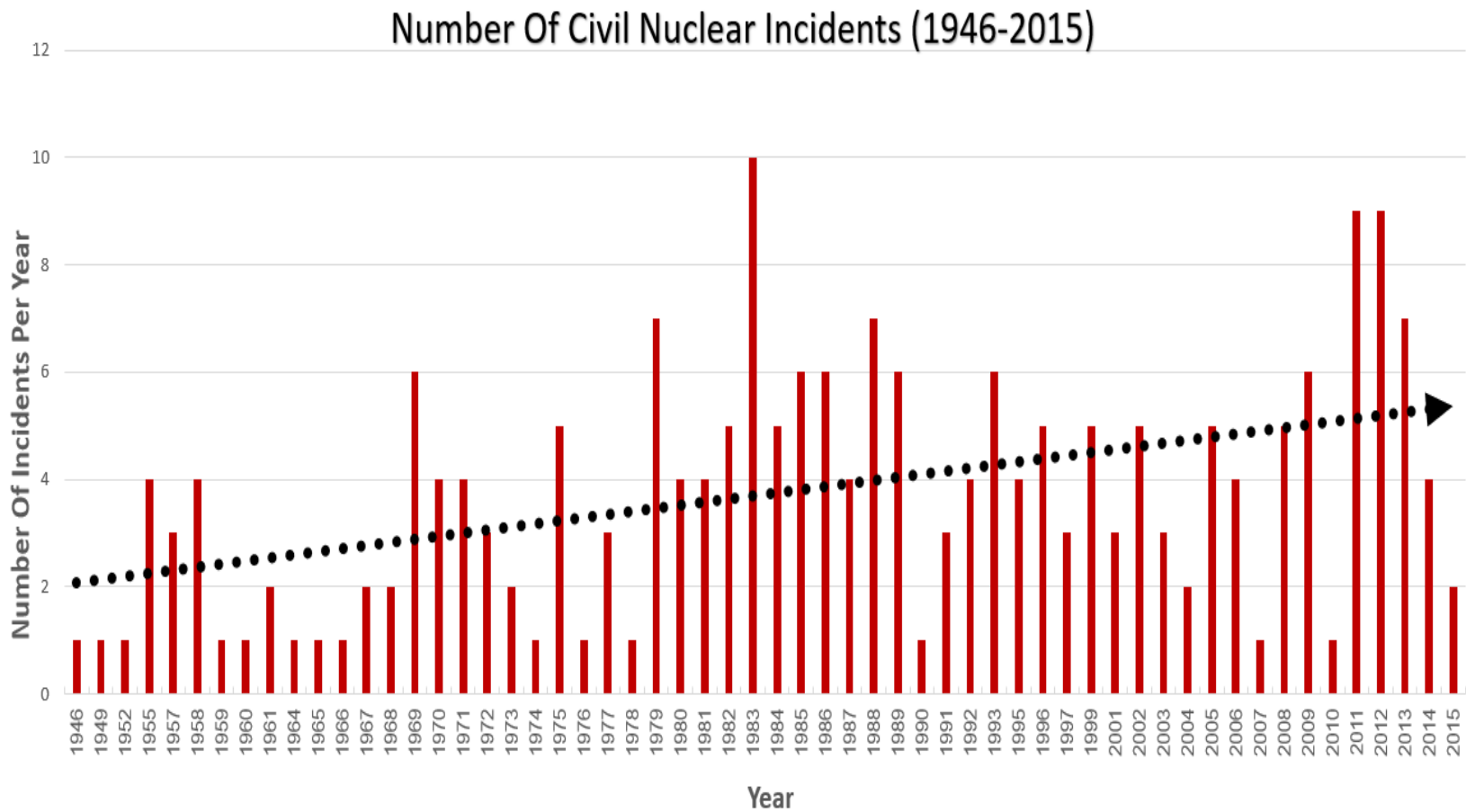

Figure1: Number of civilian (only) nuclear incidents in the world per annum 1945-2015 20

20 The graph is based on data collected by Wheatley, Sovacool \& Sornette (2016), full data sheet is available at: https://innovwiki.ethz.ch/v1/index.php/Nuclear_events_database. 
Issue no. $25 / 2018$

Figure 1 shows the increasing trend in the number of civilian nuclear incidents (from 0-7 on INES) around the world in every calendar year. Whilst the safety regulations are indeed improving with time and the number of incidents per facility is diminishing, the fact that industrial development and growing use of nuclear energy means that the total number of mishaps worldwide is increasing on an annual basis. It must be noted that the number of military mishaps is confidential, but it is possible the number is significant, and type of incident is on the serious side of potential damage, since this refers to use of weapons whose purpose is to destroy.

\section{The Need for Nuclear Defense - Researching the Past and Present and Implications for the Future}

\section{Researching the Past}

The nuclear arms race began in 1949 and to this day nuclear weapons are spread around the world. The key and most well-known incidents were the accident at Three Mile Island (U.S.A.) on 28 March 1979, the reactor disaster at Chernobyl (Ukraine, U.S.S.R.) on the night between 25-26 April 1986, and the disaster at Fukushima (Japan) on 11 March 2011 after a strong earthquake and tsunami hit Japan, which constitutes the most up to date example of the constant need for readiness. These accidents led to pollution of enormous areas and evacuation of millions, and led to death, injury and property damage.

Field research included tours at accident sites and interviews with senior operators who experienced the incidents in real time.

Since World War II, incidents have occurred in which tens or more nuclear bombs have been lost around the world (Solomon, 1988).

\section{Researching the Present}

Today, the intensive nuclear arms race between countries, headed by North Korea, strengthens geopolitical tensions and illustrates just how much danger still exists.

Despite attempts to calm and explain that North Korea's desire for nuclear weapons derives from its desire to remain protected after the Cold War, the researcher Pollack (2017) stated that North Korea's conduct is not necessarily rational, and it is possible that it derives 
Issue no. $25 / 2018$

from a messianic sense, therefore it is impossible to know whether it will make use of a nuclear attack once it has achieved nuclear weaponry capability.

\section{Need for Nuclear Defense - Implications for Our Future}

The research revealed that the nuclear arms race will not end in the near future and nuclear power will remain a part of humanity for the foreseeable future and the need for a nuclear defense model is critical.

As long as nuclear power is part of humanity, the next nuclear catastrophe is not a question of 'if', but a question of 'when'. Despite this, countries around the world do research the matter in-depth, do not learn lessons or arrive at conclusions from nuclear events so as to improve future coping. An analysis and in-depth examination of events, as carried out in the research and constructing the ONDM model, leads to the conclusion that lessons from past events were not learned, and that over the years decision makers have made the same mistakes over and over again, which puts world citizens in real danger (Baverstock \& Williams, 2007; Dallos, 2013; Froggatt et al., 2013; Greenhalgh, 1980; IAEA, 2013; WISE, 2011; WNA, 2017; WNN, 2016; Wood \& Shultz, 1988) ${ }^{21}$.

\footnotetext{
21 These are the documents making up the comprehensive reports on the conduct of events and countries during the aforementioned nuclear events. Studying the data in these reports shows recurring essential failures, lack of operational preparedness before, after and during event handling, failures to reveal information and deal with the population, lack of cooperation, and more. These failures recur in all events, with which the current model will deal.
} 


\section{Research development of the ONDM}

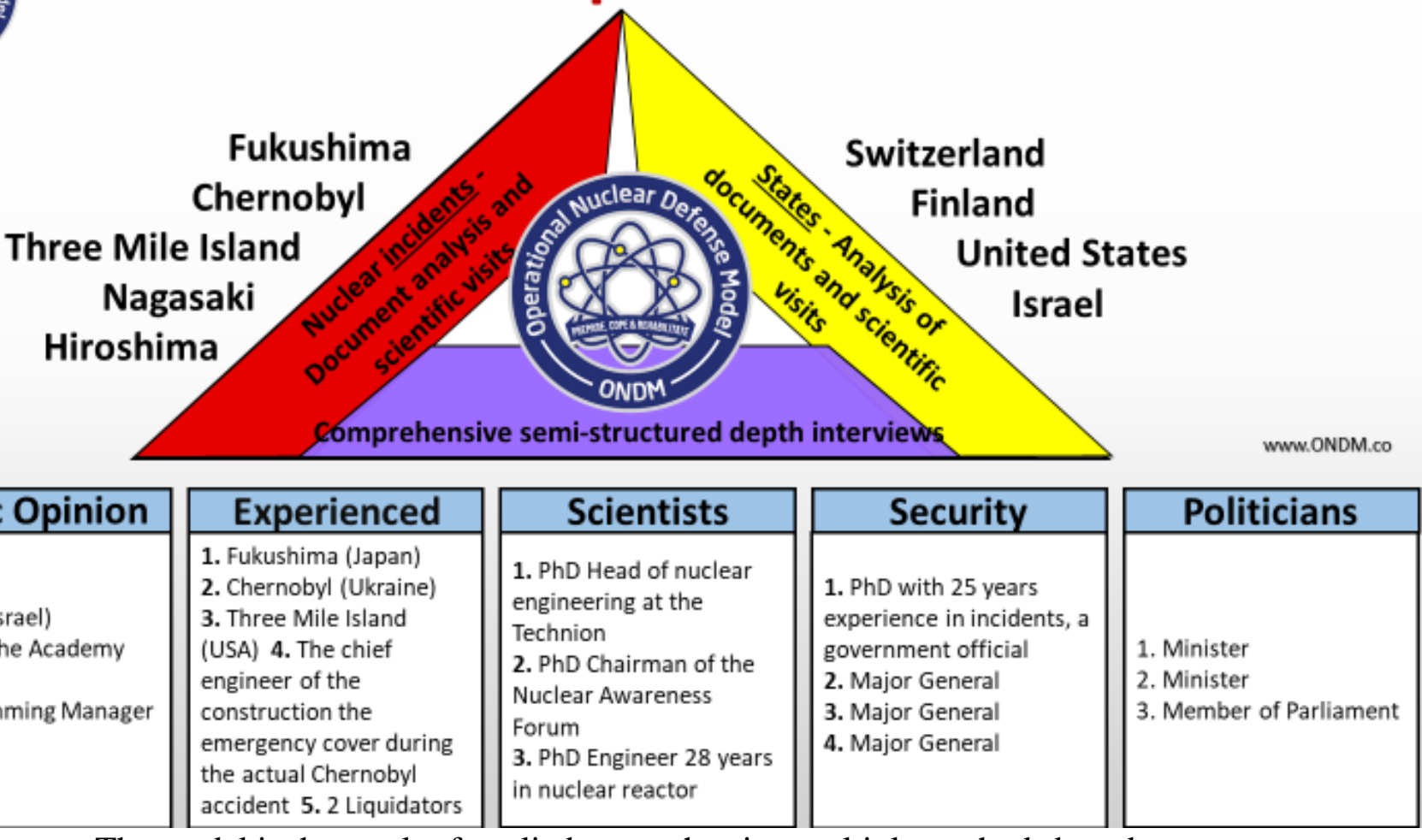

The model is the result of applied research using multiple methods based upon:

1. Researcher's experience

2. 18 in-depth interviews -3 senior nuclear scientists, 3 senior politicians, 3 military personnel with rank of Major General or above, 3 people who were actual participants in nuclear incidents around the world, 1 The chief engineer of the construction the emergency cover during the actual Chernobyl accident case, 2 Liquidators and 3 senior public representatives.

3. 3 field studies - including guided scientific visits to polluted areas, measurement with use of protective equipment, areas where incidents occurred and also swallowing in practice Lugol's iodine.

4. 9 case studies - analysis of 5 major nuclear incidents: Fukushima, Chernobyl, Three Mile Island, Nagasaki and Hiroshima and an analysis of arrangements preparations in 4 countries: Switzerland, Finland, the U.S.A. and Israel. 
Issue no. $25 / 2018$

\section{Failures in Existing Models and Future Preparedness for a Nuclear Disaster}

\section{What causes failure?}

\section{Preparedness for scenarios with low attribution}

A review of existing models reveals that the core problem of defective future planning is that world countries operate scenarios with low attribution such as a dirty bomb or small leak. In other words, various countries have high readiness and ability to cope appropriately with events on a 0-3 level on the INES scale ${ }^{22}$, but there is neither sufficient nor high enough preparedness for events on a 6-7 level on the INES scale, such as those which occurred in the past.

One can argue that the widespread assumption of a low probability of a large scale nuclear disaster has led to complacency and deficient future planning.

\section{$1.1 \quad \underline{\text { Reasons }}$}

As of January 2017, 754 nuclear reactors have been built for civilian purposes. Over the years, some have closed and for some the construction was never completed, and today there are approximately 60 reactors under construction and 450 active nuclear reactors (BAS, 2017). Although all attempts are made during construction to minimize any possible mishap, history has shown us that they are not immune from mishaps.

A historic examination of nuclear safety between 1946 and 2014 found that there were 216 civil nuclear events at different levels. It is important to note that military nuclear events are highly confidential and tracing data is problematic.

The nuclear event frequency has been in constant decline since the 1970s, and as of 2015 all nuclear plants have a 0.002-0.003 safety events per annum per plant. However, with reference to event severity, it was found that event numbers have only declined in light and medium nuclear events, and there has been no decline in catastrophic disasters. In other words, there is a lower probability of light and medium accidents per plant, but an

\footnotetext{
22 The INES scale is a scale to measure nuclear events. 0-3 are the lowest levels defined as incidents in contrast to the highest levels of 4-7 defined as accidents and it is these that result in real damage. The events at Chernobyl and Fukushima were ranked at the highest level on this scale, level 7.
} 
Issue no. $25 / 2018$

\section{accident that does occur will most likely be at a high level with serious environmental} consequences. The declining trend derives from the fact that over the year, many safety regulations have been designed and have led to a decline in moderate nuclear events, but nonetheless one still cannot prevent serious and unexpected accidents, defined as runaway disasters, such as natural disasters or human errors, accidents of the sort that no model expected (Wheatley, Sovacool \& Sornette, 2016).

A key example of this was the event in Fukushima, Japan, where the country had very effective models to cope with tsunami, but none whatsoever to deal with a nuclear mishap (Froggatt et al., 2013). Despite these findings, many countries are not at all prepared for a large scale nuclear disaster because such a disaster is catalogues as having a very low probability and therefore countries do not invest resources in planning how to deal with it.

An example of a problem of future coping can be seen in the risk management model of the Dutch government. The model is based on a widespread risk assessment model called National Risk Assessment (NRA). How events are handled is based on the severity of damage from an event versus the probability of an event occurring, where the model presents detailed means of coping for events whose probability of occurring is higher, but very devastating events with a low probability of occurring are outside the range of its treatment. Thus, the country is prepared to cope with disasters such as the outbreak of a disease, but is completely unprepared for a large nuclear disaster (Mennen, 2013). Because the dominant component in existing risk management models is the probability of an event occurring, they are neither practicable nor do they provide an answer for coping during an emergency. The most catastrophic events are the rarest or most malicious - and these conditions make using probability irrelevant (Eijffinger, 2012).

One conspicuous threat that is almost never referred to in existing models (Exists as an option but not in a treatment model) is nuclear terror. Nuclear terror can take various forms, starting with an improbable but existing scenario in which a radical group acquires a nuclear weapon to scenarios such as any form of terror attack on a nuclear power station or detonating a dirty bomb, which is a regular bomb attached to radioactive material that is spread. According to AEA existing data, tons of fissionable material disappeared, was lost or stolen between 1993 and 2014, and even reports of stolen material are on the increase (Evas, 
Issue no. $25 / 2018$

2015). Just between 2013-2016, 683 incidents of lost or stolen fissionable material were reported, and of those at least 329 were serious incidents suitable and sufficient for the creation of a dirty bomb. In the U.S.A. alone, there were 46 cases of theft and 57 cases of lost material, and half of these included material usable for the creation of a dirty bomb. Moreover, other remarkable events have occurred in places such as the Middle East and Eastern Europe - over recent years Turkish authorities arrested two people on the Syrian border with 1.24 kilograms of cesium, nuclear material suitable for a dirty bomb; in November 2016, Iran reported the loss of nuclear material also fit for the creation of a dirty bomb; between 2013-2016 a number of people were arrested in Georgia and Ukraine trying to sell nuclear material such as uranium and cesium (NTI, 2017).

\subsection{Refuting the Mistaken Assumption}

In contrast to the widespread low probability argument, Wheatley, Sovacool and Sornette (2016) maintained that there was a $50 \%$ probability of one of the following catastrophic events occurring - serious blow to a nuclear facility as a result of a natural disaster will occur in the next 50 years; mishap at a nuclear facility as a result of an accident or faulty planning will occur in the next 27 years; an accident as a result of human error will occur in the next 10 years.

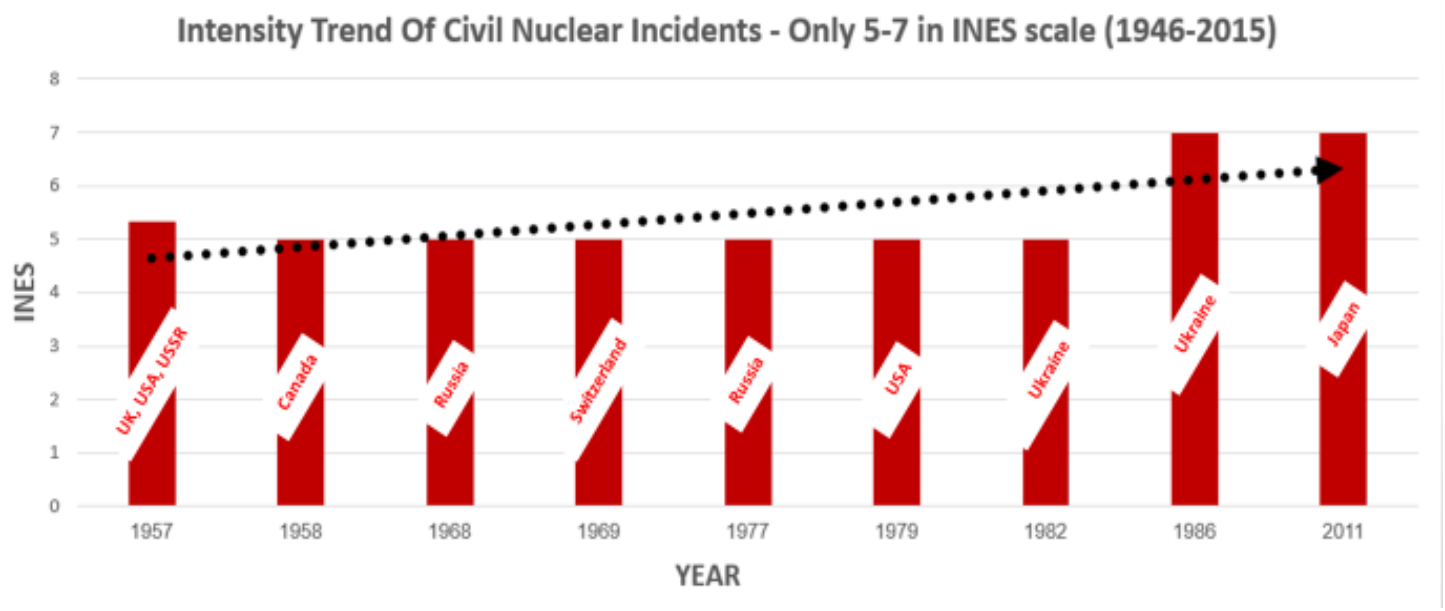


Issue no. $25 / 2018$

Figure 2: Intensity trends of large civic nuclear incidents - solely 5-7 on INES between 1946 and $2015^{23}$

Figure 2 shows that the intensity of large nuclear events (5-7 on INES) has increased over the years.

Note that in 1957, there is a deviation above intensity 5 because there were three large nuclear incidents, one at level 6 and two at level 5.

\section{Plans to Deal with an Attack Scenario and not an Incident/Accident}

As a result of the mistaken assumption that the probability of a large-scale incident is low, models were build that do not respond correctly. Nuclear accidents of the past have taught as that countries did not have suitable plans to handle disasters.

Looking at past handling, very little is known about Soviet government plans during the period in which the Chernobyl incident took place, and it appears that plans to cope with a nuclear bomb were used to deal with the reactor (not plans for a mishap at a reactor, which are different from the start). From an analysis of actions taken by the Soviet government it is clear that it was improvised without any real plan (WISE, 2011). At Fukushima too, it is clear there were no suitable plans, there were safety omissions and lack of real preparedness, and these contributed to defective management of the event (Froggatt et al., 2013; IAEA, 2013).

Looking at current coping, examining various documents and existing model to cope with civil nuclear events in various countries around the world such as the U.S.A. (USNRC, 2012), Canada (CNSC, 2015), Finland (STUK, 2017), Switzerland (CNS, 2013) and France (SGDSN, 2014), show various detailed models to cope with a nuclear attack disaster or preventing a disaster. These are technical models showing a range of scenarios to cope as a result of a failure at a nuclear reactor and ways of coping with nuclear fallout, civil damage, evacuation plans and the like. The Finnish model, for example, emphasized the fact that many lessons were learned from the event at Fukushima and failures there, but from its review, one can understand how lacking preparedness is - only in 2014 was the first drill

23 The graph is based on data collected by Wheatley, Sovacool \& Sornette (2016), full data sheet is available at: https://innovwiki.ethz.ch/v1/index.php/Nuclear_events database 
Issue no. $25 / 2018$

carried out at one of the four nuclear power stations in the country simulating a failure in two reactors simultaneously, and even as part of the report's conclusions, the action plan requires only minor changes in overall preparedness for a disaster on the part of the civilian action forces.

On the fact of things, this is an appropriate response, but Wheatley, Sovacool and Sornette (2016) argued that even these detailed models do not provide answers for a large scale incident. The aforementioned nuclear risk management model failed in the past to predict serious nuclear accidents and failed to deal with them properly. This model does not correctly evaluate the level of danger and damage caused by various events, the predications and probabilities of an accident were based on optimistic, unreal, estimations such as those characterized by small scale incidents. The model minimized the probability of a serious nuclear accident taking place and provided responses to other scenarios, but not the most serious of all.

Although many countries assume that they can provide a response to a future nuclear disaster, and the review of countries' means of coping today, it appears that most countries updated their safety regulations regarding future nuclear events - but the models available to them do not provide a response to the most important and sever nuclear incident of all. Many countries demonstrated various improvements and technical models to deal with nuclear events, but these are tactical actions that are not accompanied by long-term strategic thought. Diverse tactical teams at departmental, divisional and even brigade level have been established in many countries, carrying out readiness drills for nuclear events and similar disasters (CBRNE defense). Many countries have such teams as part of their armed forces - including Argentina, Brazil, U.S.A, Russia, India, EU member states and others. These include equipment to monitor and clean radioactive fallout, emergency vehicles for immediate treatment such as fire engines, abilities to deal with those injured by nuclear and chemical weapons, and more.

However, the argument is that technical equipment and tactical thought do not provide a sufficient response, and equipment is ineffective in dealing with a large-scale event without overall policy at decision making and international level. A very dangerous conclusion is that professionals in the field report to their superiors, for example 
Issue no. $25 / 2018$

politicians and heads of state that they have a certain solution for a large scale nuclear mishap, which in fact, in the best case, is not accurate. This partial information is passed on as part of mistaken and similar reference to different levels of nuclear events. That is to say, there is no critically aware distinction between dealing with a nuclear event at level 0-3 according to INES and large- scale events at level 4-7 on the INES. In other words, some deception derives from the belief that a particular country does have a solution available.

It appears that despite the fact that many countries assume they have a response for a future nuclear disaster, models available to them do not provide a response to the worst and most important nuclear incident. This complacency among powers regarding a large- scale incident because of the low probability of it occurring is not rational and has the potential for devastating damage as history has proven.

\section{Conclusions from Failures and Their Assimilation in the Model}

There are many elements in managing a large emergency events, which the researcher knows personally because of his role, that, when adhered to, can save lives and failing to refer to them can lead to significant damage that could have been prevented. Even the most detailed preparedness plans are limited and do not refer to the many dimensions that make up handling a nuclear disaster at the level of decision makers. Some of these aspects are significant points and will be presented in the next section, constituting the basis for the ONDM model to deal with nuclear disasters.

\section{Conclusions and Lessons Learned Included in the ONDM Model}

1. (Lack of) international cooperation: as a result of in-depth investigation one can make a basic assumption that international cooperation is essential for a model for nuclear defense and successful handling of a large scale nuclear event. This is because an event of this scale has a wide territorial range of damage and environmental effect, especially in European countries, which are a number of sovereign countries over a relatively small area in which any event affects many countries (Saurugger, 2014). The Finnish model also 
Issue no. $25 / 2018$

emphasizes and describes the importance of cooperation between the Nordic countries in dealing with a nuclear event (STUK, 2017).

The importance of the principle of cooperation also arose in the formal discussions of WENRA and HERCA in 2014, which also emphasized the supreme importance of cooperation between countries in managing disaster, including a nuclear crisis, based mainly of cooperation and speedy revelation of information before during and after a disaster (HERCA, 2014).

Despite its importance, international cooperation virtually does not exist in the models reviewed as well as previous incidents apparently because of countries diverse interests. In addition, the current European model from 2014 emphasizes the importance of cooperation between sides (ibid.) but neither it nor various countries' plans overlap or are coordinated, which make successful international handling difficult (ibid).

Furthermore, we are witness to countries around the world, as well as in Europe, in which each one plans for a nuclear crisis according to its own interests. Not only this, even today we see information being hidden and a lack of cooperation in an up to date event atmospheric measurements in November 2017 showed that a light radioactive cloud over Europe, whose source is likely to be in the Ural Mountains in Russia. Nevertheless, the Russian government denies that there was any problem and refuses to cooperate with European governments to investigate the issue thoroughly (Sample \& Willsher, 2017).

2. Defective nuclear evacuation ratio: The lack of readiness among countries' civilian population leads to defective evacuation ratios and destructive results of the evacuation and not the event itself. My conclusion is that the evacuation ratio is $1: 10$, that is if an original authorities' plan showed evacuating X people, in reality 10X people were evacuated. For example, in Fukushima, the original plan was to evacuate an area of $3 \mathrm{~km}$ around the reactor, and in the end the evacuation was a radium of $30 \mathrm{~km}$ (IAEA, 2013; WNA, 2017). In Chernobyl the situation was even worse, when at the start the Soviet Deputy Minister of Energy maintained there was no necessity to evacuate civilians, three days afterwards 43,000 civilians were evacuated from Pripyat, a few kilometers from the facility, and in the end, the evacuation radius was 30 square kilometers, 10 times greater than the original evacuation of Pripyat, at a 2-3 kilometers radius from the site (WISE, 2011). 
Issue no. $25 / 2018$

This circumstance emphasizes the ineffectiveness of existing plans to deal with the psychological effect on the public.

3. Casualties from faulty handling and not nuclear radiation: From data examined it emerged that most were neither killed nor injured in the nuclear event itself. In Fukushima, reports described that no one was killed as a direct result of the leakage. Nonetheless, 6 firefighters who dealt with the leakage in the first hours of the disaster were killed, but not from radiation and about 1600 people were killed in various disasters and accidents during the enormous evacuation that occurred and it defective management (WNA, 2017). This is a known and recognized problem in all risk and disaster management, and the need to limited wide range injuries and essential and can be dealt with as a logistical problem.

4. Lack of public awareness of damage extent: The nuclear subject, by its nature, is surrounded in secrecy and is highly classified. Keeping this issue as a taboo leads to confusion in the security system and among citizens, increases panic, and all this is unnecessary. It is important to understand that a large scale nuclear disaster does not constitute a complete annihilation of the population, whether it is an accident or military $\operatorname{attack}^{24}$. Therefore, it is important to prepare and understand that there is things to do after a nuclear event, and as such it is important to be ready and also important to prevent panic and understand that it is possible to deal with a large scale nuclear event.

5. Public at the center - guidelines for and communication with the public: Existing models make emergency services, governments and other bodies aware, but the most important player, the public itself, is completely unaware. Faulty handling of a nuclear disaster is expressed by how the public copes as well, something which has been highlighted in previous nuclear events. In Fukushima, the government lied to the public, hid information for a long time and even cooperated with the company that operated the reactors and presented the disaster and its extent as smaller than it actually was (Froggatt et al., 2013). The event at Chernobyl was also really hidden and it took 18 days from the event happening to

\footnotetext{
24 Comprehensive nuclear war defined as mutually assured destruction (MAD) is a situation in which one power will destroy another completely, a possible situation when considering the number of nuclear weapons worldwide. Despite this, realistically observing the threats facing us it is more likely that nuclear weapons will not be used as part of overall destruction by North Korea or Iran, and therefore a countries infrastructure will not be completely annihilated, and the way in which a country deals with pointed events can greatly affect the extent of damage, injury to the population, coping efforts and rehabilitation
} 
the government admitting it officially (WISE, 2011). Past events teach us that information was late, minimal, confusing at best, unreliable and disorganized.

6. Psychology and fear: Lack of information, catastrophic myth, leaders who are not prepared to face the cameras and turn to citizens - all these led to panic, loss of control and lack of trust, which do not just contribute to the management of a nuclear disaster, but also to needless casualties. Lack of information and not understanding decision makers' circumstances also lead the public to coping deficiently with the situation based on mistaken truth.

7. Multiple bodies, committees and authorities - complicates handling the problem: A significant aim in handling a large scale nuclear disaster is to reduce bureaucracy by reducing the number of bodies and circles needed to deal with the problem. In Fukushima there were a number of handling circles responsible, which made dealing with the problem more difficult, and prominent in this was the government and company operating the reactors who could not agree who was responsible for treating, cleaning, funding and rehabilitating the area (IAEA, 2013). This was also the case in Pennsylvania U.S.A. during the Three Mile Island accident, where lack of willingness led to awful coordination between various state authorities and between the state and federal bodies (Wood \& Shultz, 1988). Today too, for example in an examination of preparedness in the U.S.A., there is a comprehensive report for dealing with nuclear accidents (USNRC, 2012) and there is also a comprehensive report of military bodies and defense units CBRN to deal with a similar event (DTIC, 2016). There is overlap between these authorities and bodies, which can create confusion and difficulties in dealing with an event in real time.

The ONDM model provides a fast, bureaucratic response allowing for continuous and speedy treatment during an incident.

8. Under insurance: The amount of money needed to care for casualties of nuclear accidents was not covered in previous nuclear accidents. At both Chernobyl and Fukushima, the damage cost much more that the amount allocated by the Treaty of Brussels for compensation at 1.5 billion Euro. Treatment of the accident at Chernobyl was put at between 75-360 billion Euro and the accident at Fukushima required a sum of between 48189 billion Euro (Froggatt et al., 2013). It is always difficult to estimate damage in a nuclear 
Issue no. $25 / 2018$

event, and it is necessary to resolve and understand this as part of preparedness for an event from an economic point of view. These facts raise troubling questions about insurance coverage and whether insurance companies should pay for damage that the bodies did not prepare for how to reduce it - insurance liability. In other words, a body, even if it purchased expensive insurance but does not prepare for the required incidents, leaves a very useful and legal opening for insurance companies to avoid paying.

\section{Worthy Response to the Problem: the ONDM Model}

The ONDM model provides a comprehensive and multi-dimensional response to all the above and should successful deal with serious nuclear accidents at level 6-7 on the INES scale. The model includes 17 macro stages describing how to act before, during and after a large scale nuclear event under 4 sets of automated, methodical, systematic steps preparatory actions before an event; actions during an event, immediate rehabilitation actions after an event; long-term rehabilitation actions, which provide a defense chain envelope with overall integrated aspects for every stage of an event. These actions were built through in-depth analysis of countries and incidents, field research in Chernobyl, Finland, the U.S.A. and Israel and after professionalization and establishing an operational team of scientists, decision makers and senior officials from emergency organizational around the world.

As part of constructing the model and creating preparedness for a nuclear event, the ONDM team created professional concepts and terms to help decision makers prepare for a large-scale scenario, for management during an emergency and rehabilitation after an incident:

Basic definitions concepts for dealing with a nuclear incident defined by ONDM team:

1. ONDM (TM) Nuclear Evacuation Ratio: Ratio between number of population who received evacuation orders and the number of actual evacuees.

2. ONDM (TM) Nuclear Overreaction Effect: The effect of overreaction amongst the public and decision makers that is expressed by panic, radicalization and desire for 
Issue no. $25 / 2018$

exaggerated safety terms. Overreaction caused by a lack of information substantially increases the chance that the authorities will lose control of an event.

3. ONDM (TM) Nuclear Operational Maturity: The levels of preparedness of a country, city, organization or authority entrusted with dealing with a nuclear event.

4. ONDM (TM) Nuclear Rehabilitation Speed: The amount of time in hours that it would take a country, city or organization to return to $50 \%$ of their normal functioning as it was prior to an event.

5. ONDM (TM) Nuclear Spontaneous Survival Ability: The amount of time in hours that a country, city or organization is able to survive in a defined territory without external help.

6. ONDM (TM) Rehabilitation Chances of Nuclear Surviving: Estimated percentage of ability to rebuild a defined territory after receipt of maximal internal and external aid.

7. ONDM (TM) Effect of Efficient Nuclear Aid: The level of influence that external aid provision has on a defined territory.

8. ONDM (TM) Nuclear Defense Awareness: Levels of awareness among individuals, organization, emergency services, government, authorities and the state about nuclear defense.

9. ONDM (TM) Pre-impact ONDM scale: Calculated mark for level of management, functioning and survival of a defined territory in case of a nuclear incident before an event.

10. ONDM (TM) Post-impact ONDM scale: Calculated mark for level of management, functioning and survival of a defined territory in case of a nuclear incident after the incident. The mark is comparative to management and functionality of other incidents around the world.

11. ONDM (TM) Operational Nuclear Defense Model - ONDM - an operational model for nuclear defense, made up of 17 macro-stages, which are categorized into 4 sets of automated, methodical, systematic steps defense actions: preparation, operation, immediate and long-term rehabilitation. The model is founded on basic concepts in the field of nuclear defense. 
Issue no. $25 / 2018$

Implementing the ONDM model is a critical step in defense, and its contribution to a city or country during an emergency is extremely high. Lessons and means of coping learned from in-depth research have been adapted in this system and will form a strong foundation for better handling of future catastrophic events.

\section{Conclusion}

As described, today preparedness for a large scale nuclear disaster is deficient and one must remember that we remain at risk of an event as a result of arms, nuclear facilities, terrorism, human error or natural cause. The applied research analyzed and catalogued past mistakes, and through them and the experience of the researcher the ONDM model was constructed to deal with a large scale nuclear event at all stages, before during and after an event. The model is important not only for decision makers but for the general public that may be injured from an event that is not appropriately handled, because the time has come that we learn from past mistakes, analyze them and successfully realize the conclusions.

\section{References}

- BAS. (2017). Global Nuclear Power Database. Bulletin of the Atomic Scientists, https://thebulletin.org/global-nuclear-power-database.

- $\quad$ BAVERSTOCK, K., \& WILLIAMS, D. (2007). The Chernobyl accident 20 years on: an assessment of the health consequences and the international response. Ciência \& saúde coletiva $12(3), 689-698$.

- $\quad$ CNS. (2016). $6^{\text {th }}$ National Report of Switzerland to the Convention on Nuclear Safety. Implementation of the Obligations of the Convention on Nuclear Safety.

- $\quad$ CNSC. (2015). Study of Consequences of a Hypothetical Severe Nuclear Accident and Effectiveness of Mitigation Measures. Canada Nuclear Regulator.

- DALlOS, G. (2013). Beyond Nuclear: The Triple Challenge facing Japanese Utilities. Greenpeace International. 
Issue no. $25 / 2018$

- DOBSON, A. P. (2002). Realism (International Relations). In: Edward J. BLUM, Cara BURNIDGE, Emily CONROY-KRUTZ, David KINKELA (editors): America in the World, 1776 to the Present, Charles Scribner's Sons publication, 878-881.

- DONNELLY, J. (2000). Realism and international relations. Cambridge University Press.

- DTIC. (2016). Chemical, Biological, Radiological, and Nuclear Response. Joint Publication 3-41, US military.

- $\quad$ EIJFFINGER, S. (2012). Rating Agencies: Role and Influence of Their Sovereign Credit Risk 5 Assessment in the Eurozone. Journal of Common Market Studies 50(6), 912921.

- $\quad$ EVAS, E. (2016). What does "nuclear terrorism" really mean?. Bulletin of the Atomic Research Journal, https://thebulletin.org/what-does-nuclear-terrorism-really-mean9309.

- $\quad$ FROGGATT, A., MCNEILL, D., THOMAS, S., \& TEULE, R. (2013). Fukushima Fallout. Greenpeace International.

- GREENHALGH, G. (1980). Three Mile Island. In The Necessity for Nuclear Power (pp. 189-194). Springer, Dordrecht.

- HERCA. (2014). New European Approach for Cross-Border Emergency Preparedness. http://www.herca.org/herca_news.asp?newsID=41.

- $\quad$ IAEA. (2013). Fukushima Nuclear Accident Update Log. https://www.iaea.org/newscenter/news/fukushima-nuclear-accident-update-log-52.

- $\quad$ MENNEN, M. G. (ed.) (2013). National Risk Assessment 2011. Project Number: E/609042/01, National Institute for Public Health and the Environment (RIVM).

- $\quad$ MORGENTHAU, H. J. (1978). Politics among Nations: The Struggle for Power and Peace, 5th ed. Revised by Alfred A. Knopf.

- $\quad$ NTI. (2017). Global Incidents and Trafficking Database Interactive Maps. Nuclear Threat Initiative Project, http://www.nti.org/analysis/articles/global-incidents-and-traffickingdatabase-interactive-maps/

- $\quad$ ÖMER, G. (2008). Definition and management of international crises. Center for strategic research Republic of Turkey Ministry of Foreign Affairs. 
Issue no. $25 / 2018$

- $\quad$ POLLACK, J. D. (2017). No exit: North Korea, nuclear weapons, and international security. Routledge.

- $\quad$ REDD, S. B., \& MINTZ, A. (2013). Policy perspectives on national security and foreign policy decision making. Policy Studies Journal 41(S1), S11-S37.

- $\quad$ SAMPLE, I., \& WILLSHER, K. (10.11.2017). Nuclear accident sends 'harmless' radioactive cloud over Europe. The Guardian, https://www.theguardian.com/world/2017/nov/10/nuclear-accident-in-russia-or-kazakhstansends-radioactive-cloud-over-europe.

- $\quad$ SAURUGGER, S. (2014). Europeanisation in times of crisis. Political Studies Review 12(2), 181-192.

- SGDSN. (2014). National response plan: major nuclear or radiological accidents. Prime minister office republic of France.

- $\quad$ SOLOMON, K. (1988). Sources of radioactivity in the ocean environment: From low level waste to nuclear powered submarines. Journal of hazardous Materials 18(3), 255-262.

- $\quad$ STUK. (2017). Finnish report on nuclear safety. Finnish 7th national report as referred to in Article 5 of the Convention on Nuclear Safety, STUK-B 205.

- USNRC. (2012). Modeling potential reactor accident consequences. U.S. Nuclear Regulatory Commission.

- $\quad$ WheAtley, S., SOVACOOL, B., \& SORNETTE, D. (2016). Of Disasters and Dragon Kings: A Statistical Analysis of Nuclear Power Incidents and Accidents. Risk analysis: an official publication of the Society for Risk Analysis.

- $\quad$ WISE. (2011). Chernobyl: Chronology of a disaster. Nuclear Monitor 724, http://www.nirs.org/mononline/nm724.pdf

- WNA. (2017a). Nuclear Power in the World Today. http://www.worldnuclear.org/information-library/current-and-future-generation/nuclear-power-in-the-worldtoday.aspx

- WNA. (2017b). Fukushima Accident. World Nuclear Association, http://www.worldnuclear.org/information-library/safety-and-security/safety-of-plants/fukushima-accident.aspx. 
Issue no. $25 / 2018$

- WNN. (22.01.2016). IAEA praises reform of Japan's nuclear regulator, http://www.world-nuclear-news.org/RS-IAEA-praises-reform-of-Japans-nuclear-regulator2201164.html.

- $\quad$ WOOD, M. S., \& SHULTZ, S. M. (1988). Three Mile Island. Greenwood Press. 